\title{
OPTIMIZATION OF TIME STEP AND CFD STUDY OF COMBUSTION IN DI DIESEL ENGINE
}

\author{
Patil Vijayendra Maharu', Aashish Agrawal ${ }^{2}$ \\ ${ }^{I}$ PG Student, Technocrats Institute of Technology, Bhopal, M.P. India \\ ${ }^{2}$ Associate Professor, Technocrats Institute of Technology, Bhopal, M.P. India
}

\begin{abstract}
Study of Combustion is one of the complicated phenomenon which involves a chemical reaction at certain elements of fuel like Hydrogen and Carbon combine with Oxygen liberating heat energy and causing and increase in temperature of the gases, within the engine cylinder. IC engines involve complex fluid dynamic interactions between air flow, fuel injection, moving geometries, and combustion. Fluid dynamics phenomena like jet formation, wall impingement with swirl and tumble, and turbulence production are critical for high efficiency engine performance and meeting emissions criteria. The design problems that are encountered include port-flow design, combustion chamber shape design, variable valve timing, injection and ignition timing, and design for low or idle speeds. In Internal combustion Engines CFD may be useful to study one of the most complicated process of combustion in Engines.

In this paper a CFD in-cylinder combustion analysis are carried out on a single cylinder four stroke Direct Injection (DI) Engine. The engine is 661cc Kirloskar engine. One of the main process in CFD Analysis is the Grid Generation and defining Time step for solving the problem. Proper and improve grids will give better and accurate results, Grid Independence study has been carried out. The optimum grid is find out in previous work current work is to find optimum time step for CFD analysis three cases are studied with variation in time step from TS 1, TS 0.5 and TS 0.25 the computed data is validated with Experimental data available which are in good agreement.
\end{abstract}

Keywords: Time step Optimization, CFD Combustion Analysis and IC Engine Combustion.

\section{INTRODUCTION}

Traditional, Time and cost consuming process for engine design are achieved by manufacturing prototypes and conducting tests on them, but this are not versatile as the prototype is used for single purpose only it cannot be used for other experimentation. As high efficiency and least fuel consumption are always the areas of interest in IC Engine design. Now a days, the field of computation is boosted by power of modern computers and workstations. CFD has found its applications in Diesel engine combustion. This method is widely used in industry not only for engine analysis but for a complete vehicle analysis.[2] CFD approach can be a tool for gaining insight into the incylinder combustion process of diesel engine which is already a area of interest from recent years. It is the application of three dimensional codes, which are able to solve governing flow equations and yields detailed description of velocity, turbulence, pressure, temperature, etc. Due to improvements in computational power and speed in modern computers CFD can be applied as it involves unsteady flows, high Reynold's number involved, high heat transfer and the complex variable geometry of engines. As a consequence, calculation times are usually long and computer memory requirement are large.[1]Combustion is a chemical reaction in which certain elements of fuel like Hydrogen and carbon combine with oxygen liberating heat energy and causing an increase in temperature of the gases. The conditions necessary for combustion are the presence of combustible mixture and some means of initiating the process.[8] The important combustion parameters are Pressure, temperature and volume. These parameters affect the working of the engine and has a adverse effect on the performance of the engine. If these parameters are not in controlled manner or if they are not in certain defined limits they may cause engine problems such as Knocking which may cause severe damage to the vital components of engine.

IC engines involve complex fluid dynamic interactions between air flow, fuel injection, moving geometries, and combustion. Fluid dynamics phenomena like jet formation, wall impingement with swirl and tumble, and turbulence production are critical for high efficiency engine performance and meeting emissions criteria. The design problems that are encountered include port-flow design, combustion chamber shape design, variable valve timing, injection and ignition timing, and design for low or idle speeds. [8]There are several tools which are used in practice during the design process. These include experimental investigation using test or flow bench setups, 1D codes, analytical models, empirical/historical data, and finally, computational fluid dynamics (CFD). Of these, CFD has the potential for providing detailed and useful information and insights that can be fed back into the design process. This is because in CFD analysis, the fundamental equations that describe fluid flow are being solved directly on a mesh that describes the 3D geometry, with sub-models for turbulence, fuel injection, chemistry, and combustion. Several 
techniques and sub-models are used for modeling moving geometry motion and its effect on fluid flow.

Using CFD results, the flow phenomena can be visualized on 3D geometry and analyzed numerically, providing tremendous insight into the complex interactions that occur inside the engine. This allows you to compare different designs and quantify the trade-offs such as soot vs NOx, swirl vs tumble and impact on turbulence production, combustion efficiency vs pollutant formation, which helps determine optimal designs. Hence CFD analysis is used extensively as part of the design process in automotive engineering, power generation, and transportation. With the rise of modern and inexpensive computing power and 3D CAD systems, it has become much easier for analysts to perform CFD analysis.[9]

This method also has a flexibility to vary the engine geometry and operating conditions according to the user, which is not possible in experimental approach. Thus variations of these parameters will help in new processes in engine design and analysis. The actual operations taking place inside the engine cylinder can be visualized efficiently which is not possible for experiment situations or the experimental setup for the same will be costly.

\section{CASE DESCRIPTION}

The engine studied in this paper is a single cylinder direct injection (DI) diesel engine. The engine consists of one inlet valve and one exhaust valve with a centrally located fuel injector. CFD analysis of the combustion process in this engine is carried out by numerical method using a CFD package FLUENT. The engine geometry consists of inlet manifold, exhaust manifold a fuel injector and piston bowl fig.1. During combustion in engines both the inlet and exhaust valves are closed and the combustion takes place above the piston usually known as combustion chamber. Hence, in order to reduce the computational time a simplified model having $30^{\circ}$ sector is consider for analysis. The model consists of a centrally located fuel injector and piston bowl which forms the combustion chamber fig. 2 .

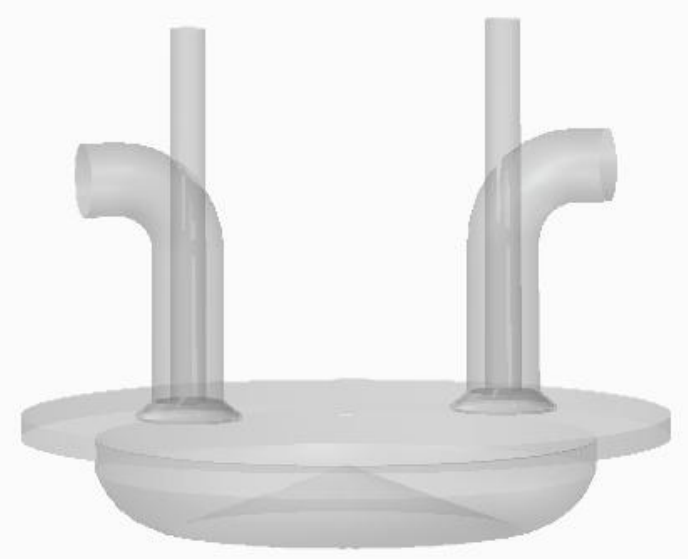

Fig - 1: Complete model of Engine.

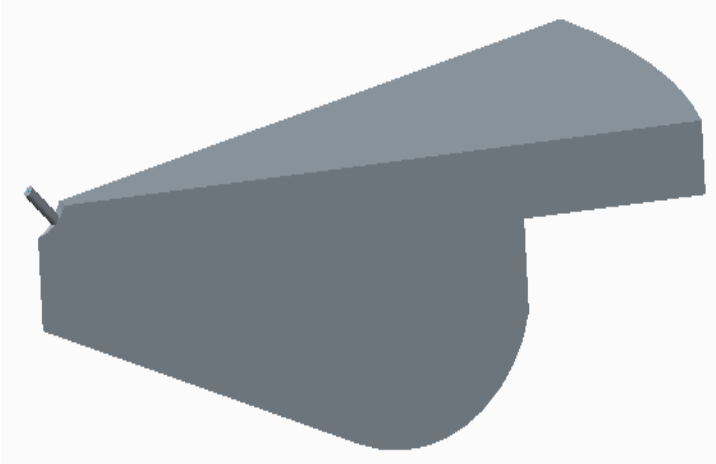

Fig - 2: A $30^{\circ}$ sector model for analysis.

Various fluid zones and interfaces are provided for different regions of a model to enhance the results and for providing accurate interactions of boundary conditions. A dynamic mesh is carried out to simulate the suction and compression process up to the point of injection. After injection the monitors are applied for getting results of combustion parameters such as pressure, temperature and volume. The main aim of this paper is to find optimum mesh size by grid independence study which will give required results. Experimental study has been carried out on a Single cylinder four stroke DI Diesel engine with variable compression ratio. The numerical results will be compared for four mesh cases and optimum mesh case will be find out which will be in good agreement with experimental results.

Table 1 shows the various engine parameters which are considered for this study.[10]

Table - 1: Engine Parameters.

\begin{tabular}{|l|l|}
\hline Parameter & Value \\
\hline Cylinder Bore & $87.5 \mathrm{~mm}$ \\
\hline Connecting rod Length & $234 \mathrm{~mm}$ \\
\hline Stroke & $110 \mathrm{~mm}$ \\
\hline Engine Speed & $1538 \mathrm{rpm}$ \\
\hline Compression Ratio & 17.5 \\
\hline Inlet Valve open before TDC & $4.5^{\circ}$ \\
\hline Inlet Valve close after BDC & $36.5^{\circ}$ \\
\hline Fuel injection start before TDC & $23^{\circ}$ \\
\hline Exhaust Valve open before BDC & $35.5^{\circ}$ \\
\hline Exhaust Valve close after TDC & $4.5^{\circ}$ \\
\hline
\end{tabular}

\section{NUMERICAL MODELING}

In order to study the process of combustion a finite volume commercial flow program has been used to solve the discretized Navier Stokes equation. The standard $k$ - $\varepsilon$ turbulence model for high reynold's numbers with wall function is used.[1]The $k-\varepsilon$ model for solving Navier stokes equation employees the eddy viscosity concept. Since $\mathrm{k}$ and $\varepsilon$ both are produced destroyed and transported by flow, one obtains partial differential equations governing their values in the floe domain.[3]The code is based on pressurecorrection method using PISO algorithm. The first order upwind differencing scheme is used in the momentum and turbulence equations.[4]The governing equations for the gas 
flow and the combustion process are Mass equations, Momentum equations and Energy equations. Finite volume method has been used to solve the discretized partial differential equations governing the mean fluid motion. The discretization of space in the appearance of cell numbers and time in the form of time stepping are set which provide a reliable indication of the suitability of the discretization settings. The time discretization is necessary to obtain the best compromise between the convergence requirements and the computing time i.e. the smaller time steps were set for initiating simulations when the crank angle reached the fuel injection timing and the TDC position.[5] A species transport model with discrete phase has been used for non premixed combustion with non adiabatic equilibrium phase model. Injection is define at specific crank angle at which the fuel injection starts and stops. The fuel temperature, pressure and mass flow rate is defined during injection. The fuel injection parameters like location of injector, size of injector, injection temperature and pressure, mass flow rate etc. are having significant effect in diesel combustion modeling.[2] The droplet model of injection with injection location is specified. The surface monitor is defined to find Pressure, Temperature and volume from $20^{\circ}$ before injection to end of combustion. As discuss earlier in Table 1 the fuel injection starts at $23^{\circ}$ before TDC means at $337^{\circ} \mathrm{CA}$ and the combustion ends at $397^{\circ} \mathrm{CA}$ hence simulation starts at $317^{\circ}$ $\mathrm{CA}$ and ends at $397^{\circ} \mathrm{CA}$. Iso surface is created to plot contours of temperature and pressure for the combustion simulation. As explained earlier that the time discretization is necessary to obtain the best compromise between the convergence requirements so time step plays a very important role in solving combustion problems. Hence, time step is varied from $1,0.5$ and 0.25 of which time step of 0.25 is found optimum for combustion analysis. The volume monitors are obtained at various zones in the form of output data with respect to flow time and time step. The number of iterations required for solving the combustion problems depends upon the time step and the CA to run. The computational time required for such simulations is more as they involved Dynamic mesh and Transient analysis.

\section{TIME STEP STUDY}

A grid generation program has been used to create hexahedral grid. As explained earlier, due to complexity of defined problem a simplified model of $30^{\circ}$ sector is used for analysis. The inlet port, exhaust port, Inlet and exhaust valve are ignored as these components does not have any significance role during combustion. Due to the fact that both the inlet and exhaust valves are closed during combustion and the fuel is injected before the end of combustion stroke i.e. at $23^{\circ}$ before TDC which means at $337^{\circ} \mathrm{CA}$. To study the process of combustion effectively simulation will be carried out some CA before fuel injection and after fuel injection. For this study the simulation will start at $317^{\circ}$ and end at $390^{\circ}$. Time step also has a significance on Combustion analysis, three cases of time step are studied for optimum results i.e. time step 1, time step 0.5 and time step 0.25. Simulations are carried out with fine grid having $2 \mathrm{~mm}$ face spacing which consists of 15130 nodes and 8413 elements. Grid having $1 \mathrm{~mm}$ face spacing was also the alternative consisting of 60797 nodes and 35154 elements, but the time required for analysis for $1 \mathrm{~mm}$ spacing grid is more which has been found by a grid Independence study. A CFD combustion simulation has been carried out for different time steps and compared with the experimental results of engine such as Pressure, Temperature and volume form which the optimum time step is find out which gives the results which are in good agreement with the experimental results. Fig 7 to Fig 9 shows the graphical comparison of different time steps for Pressure, Temperature and volume at different Crank Angles.

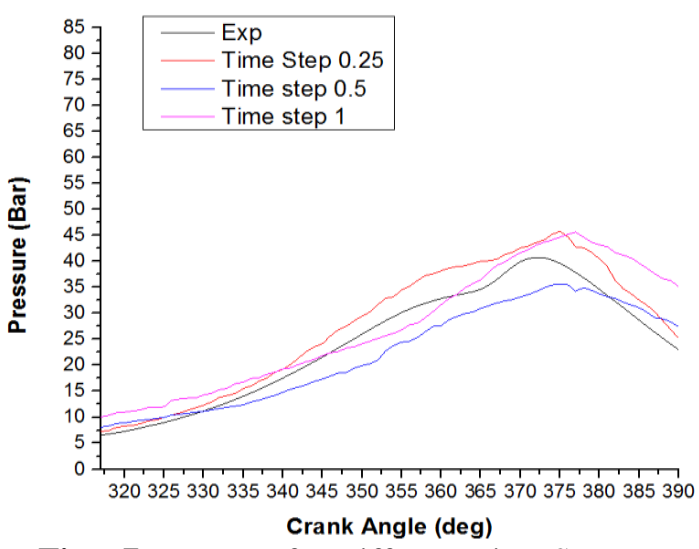

Fig - 7: Pressure for Different Time Steps.

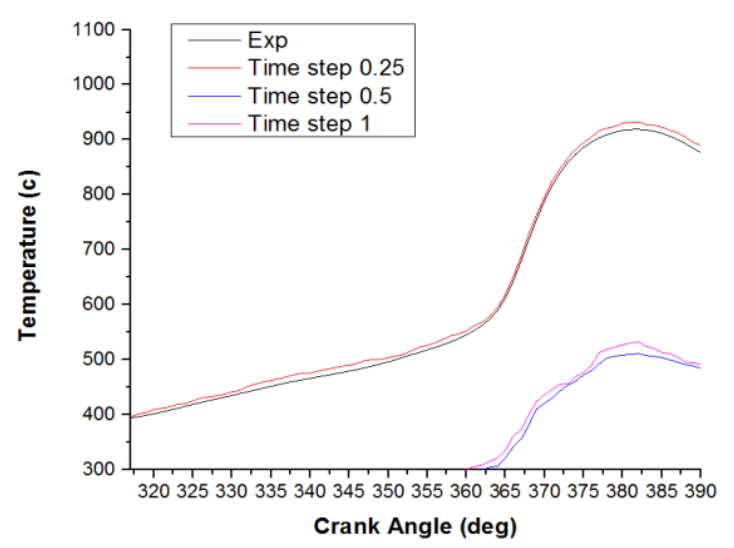

Fig - 8: Temperature for Different Time Steps.

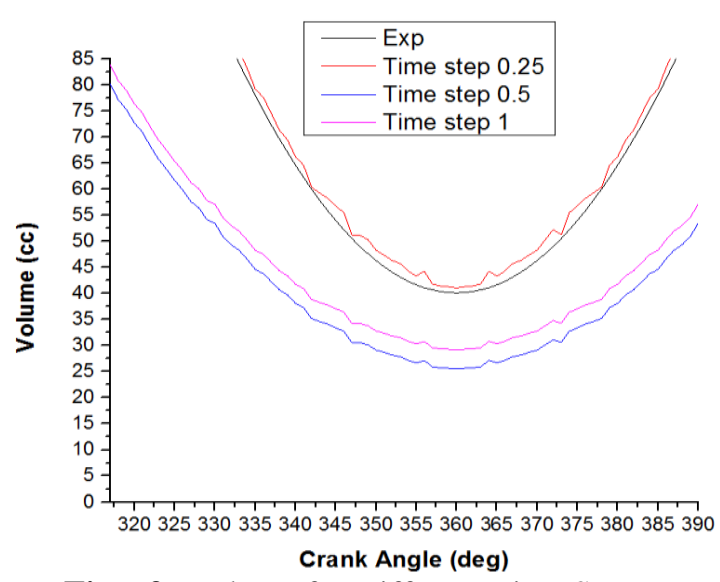

Fig - 9: Volume for Different Time Steps. 


\section{RESULTS AND DISUCSSIONS}

From Time Step study the time step of 0.25 has found better for results. The CFD analysis are carried out with time step 0.25 by using Numerical methods discussed in Numerical Modeling. The time step for analysis is 0.25 with 292 iterations. The simulation starts at $317^{\circ}$ the fuel injection starts at $337^{\circ}$ and simulation ends at $390^{\circ}$. The combustion process is studied from $317^{\circ} \mathrm{CA}$ to $390^{\circ} \mathrm{CA}$ in order to get insight on In-cylinder process and detail study of In-cylinder parameters such as Pressure, Temperature and Volume. The Experimental data obtained from VCR (Variable compression ratio Engine) is compared with CFD solution. The combustion process inside the engine cylinder can be simulated using contour plots of surface created for visualization of Temperature and Pressure at various Crank angles. The CFD simulation could give an idea of Physical Phenomenon occurring inside the engine cylinder which could not be possible in practice. Plots for various parameters such as Pressure, Temperature and volume are obtained in a tabular data format which can be plotted against Crank angle. The results are shown from Fig. 10 to Fig.15.

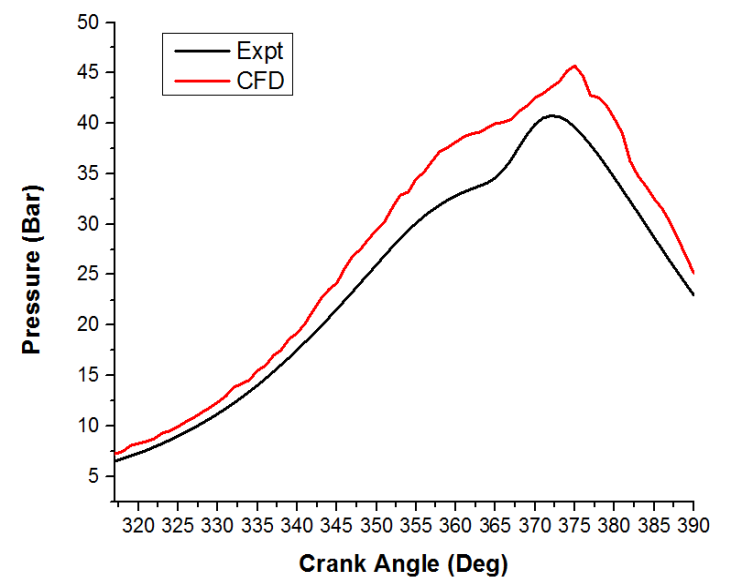

Fig - 10: Comparison of Experimental and CFD Pressure.

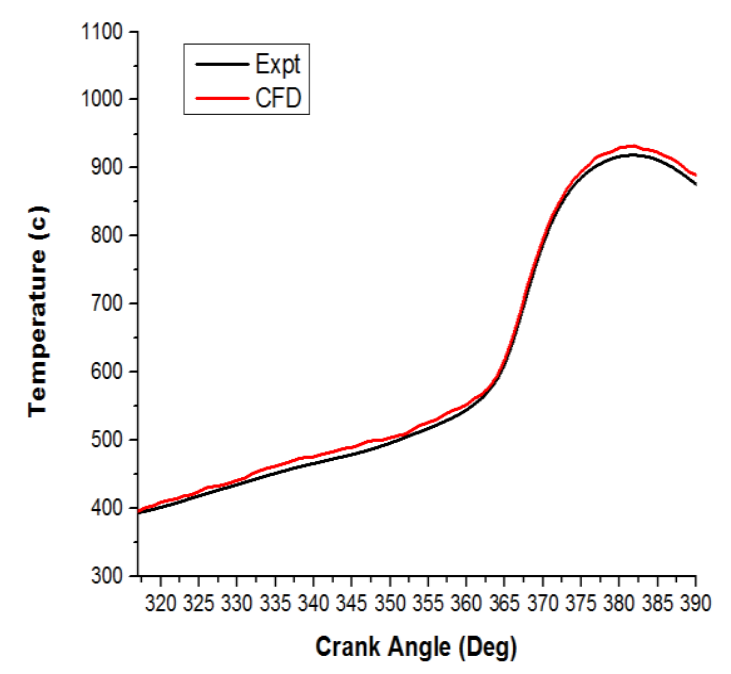

Fig - 11: Comparison of Experimental and CFD Temperature.

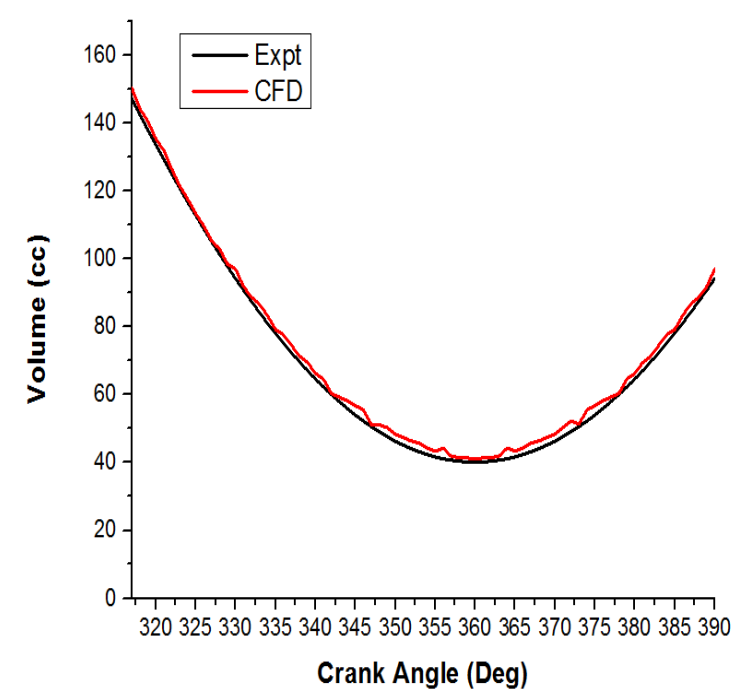

Fig - 12: Comparison of Experimental and CFD Volume.

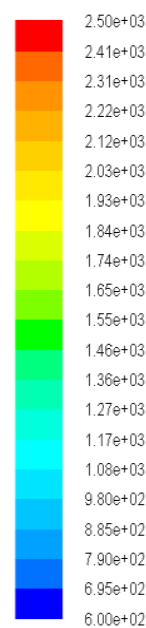

Fig - 13: Contour of Temperature at $327^{\circ} \mathrm{CA}$.

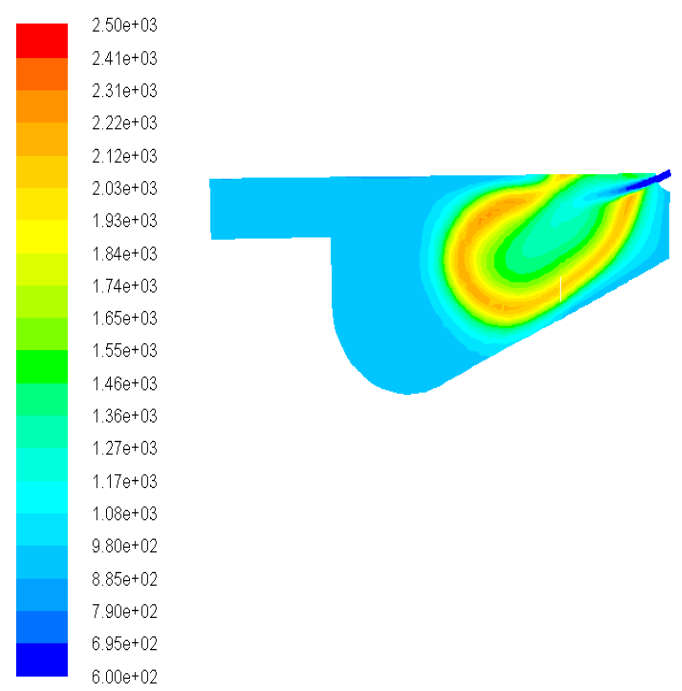

Fig - 14: Contour of Temperature at $342^{\circ} \mathrm{CA}$. 


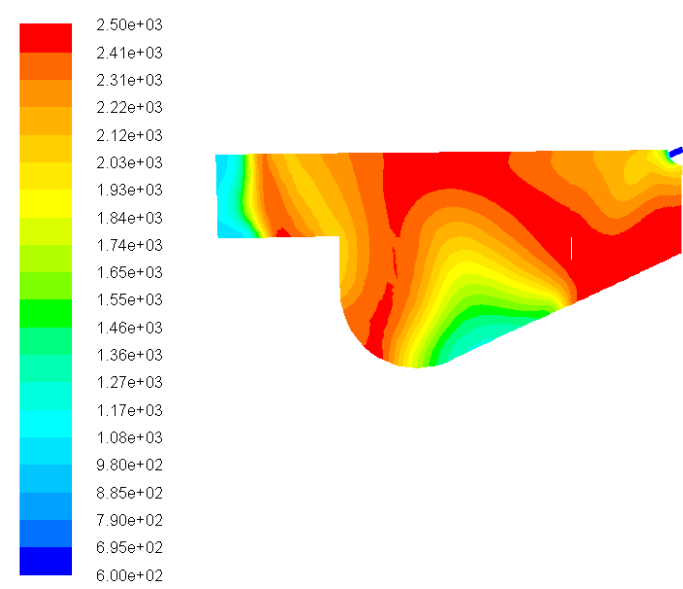

Fig - 15: Contour of Temperature at $387^{\circ} \mathrm{CA}$

\section{CONCLUSIONS}

A CFD combustion Simulation has been carried out for a four stroke single cylinder DI engine. Due to complexity of problem only a $30^{\circ}$ sector of a model is modeled in a $3 \mathrm{D}$ software. Model is defined with various Zones to define the boundary conditions and interfaces, Dynamic mesh is carried out In-cylinder simulation. Three cases of time step are considered for Time step study, from which optimum time step of 0.25 provides good results is selected. The various solver methods of a commercial CFD package is used for solving the problem.

Validation of Results is done with the good quality mesh results by comparing it with Experimental data obtained. The plots of Pressure, Temperature and Volume are plotted against Crank angle. The contours of Pressure at various Crank angles are visualized for simulation and insight to Incylinder combustion processes which is not possible practically. The plots shows that CFD results are in good agreement with Experimental results with a maximum difference of $15 \%$.

In general, this study shows that In-cylinder CFD simulation and study yield accurate results that allow improving the knowledge of combustion in DI diesel engines. The work presented in this paper insights the simulation process inside the engine cylinder, CFD has become modern tool to study the complicated process of combustion in engines, Instead of using highly cost experimental setup this technique can be adopted for combustion analysis of DI Diesel engines, which could play a very important role in engine design, research and development.

\section{REFERENCES}

[1]. F. Payri , J. Benajes, X. Margot , A. Gil, "CFD modeling of the in-cylinder flow in direct-injection Diesel Engines." Computers \& Fluids 33 (2004) 995-1021.

[2]. S GavudhamaKarunanidhi, Melvinraj C R, Sarath Das K P, G Subba Rao,"CFD Studies of Combustion in Diesel Engine."'International Journal of Engineering Research and Applications (IJERA),ISSN: 2248-9622,Vol. 3, Issue 4, JulAug 2013, pp.827-830.
[3]. S.M.Iameel Basha,P.IssacPrasad and K.Rajagopal,"Simulation of In-Cylinder processes in a DI Diesel Engine with Various Injection Timings" ARPN Journal of Engineering abd Applied Sxiences, Vol, 4, NO:1, Feb 2004. ISSN 1819 - 6608.

[4]. A.Hatziapostolou, G.Raptis, "CFD Modeling if InCylinder flow in a Variable Compression Spark-Ignited Engine"Proc. of the 9th WSEAS Int. Conf. on Mathematical and Computational Methods in Science and Engineering, Trinidad and Tobago, November 5-7, 2007.

[5]. Shahrir Abdullah, Wendy HardyonoKurniawan and AzhariShamsudeen, "Numerical Analysis of the Combustion Process in aCompressed Natural Gas Direct Injection Engine",Journal of Applied Fluid Mechanics, Vol. 1, No. 2, pp. 65-86, 2008.ISSN 1735-3645.

[6]. Wendy HardyonoKurniawan, Sharir Abdulla and AzhariShamsudeen, "A Computational Fluid Dynamics Study of Cold Flow Analysis For Mixture Preperation In a Motored Four-Stroke Direct Injection Engine"Journal of Applied Sciences 7 (19) : 2710-2724,2007. ISSN 18125654.

[7]. T.Morauszki, P.Mandli,Z.Horvath and M.R.Dreyer,"Simulation of Fluid Flow, Combustion and Heat Transfer Processes In Internal Combustion Engines" Hungarian Journal of Industrial Chemistry Veszprem.Vol. 39 (1) pp.27-30 (2011)

[8]. V.Ganesan, "Internal Combustion Engines." Second edition, Tata Mcgraw Hill ISBN 0-07-049457-6

[9]. ANSYS Fluent User Manual.

[10]. Apex Innovations, VCR Engine User Manual. 